\title{
Herbivory and Inanimate Objects in the Diet of the Oriental Ratsnake, Ptyas mucosa (Linnaeus 1758)
}

\author{
Vivek Sharma ${ }^{1}$, Amit Sayyed ${ }^{2}$, and Rita Bhandari ${ }^{3}$ \\ ${ }^{1}$ Department of Zoology, Govt. Model Science College, Jabalpur (Madhya Pradesh), 482001, India (vrks1007@gmail.com) \\ ${ }^{2}$ Wildlife Protection and Research Society, Satara (Maharashtra), 415002, India (amitsayyedsatara@gmail.com) \\ ${ }^{3}$ Department of Zoology, Government O.F.K. College, Jabalpur (Madhya Pradesh), 482005, India (ritabhandari06@yahoo.com)
}

$S^{n}$ nakes typically are carnivorous, with various species consuming a variety of invertebrate and vertebrate prey, often in accordance with size of predator and prey (e.g., Greene 1997). Scavenging also has been recorded in a number of snake species (e.g., DeVault and Krochmal 2002), but reports of herbivory and the consumption of inanimate objects are rare. D'Abreu (1911) noted the presence of a stone in the stomach of a Checkered Keelback (Xenochrophis piscator) and suggested that it might serve a similar purpose as stones consumed by crocodiles and birds. Dalziel (1937) mentioned snakes feeding on fruits under Vitex micrantha, a tropical African tree. Mookerjee (1946) reported an Indian Python (Python molurus) that had consumed four mangoes infested with insect larvae. Irvine (1953) noted snakes feeding on the yellow fruits of Momordica foetida, a perennial African vine. Perry (1954) indicated that her pet Leopard Snake (Zamenis situla) opportunistically swallowed cheese rinds before reverting to its normal carnivorous diet. Lillywhite et al. (2008) discussed the consumption of marine plants by Florida Cottonmouths (Agkistrodon conanti). Herein, we report a case of herbivory and instances of Oriental Ratsnakes (Ptyas mucosa) feeding on inanimate objects.

At $1132 \mathrm{~h}$ on 19 January 2008 on the periphery of a busy vegetable market in Satara, Maharashtra $\left(17^{\circ} 41^{\prime} \mathrm{N}, 74^{\circ} 0^{\prime} \mathrm{E}\right)$, an Oriental Ratsnake (Ptyas mucosa) with a total length of $-173 \mathrm{~cm}$ (Fig. 1) swallowed an onion with a diameter of $-5.5 \mathrm{~cm}$. With the onion $-40 \mathrm{~cm}$ behind the head, the snake started writhing and then died in -3 min. An explanation for such unusual feeding behavior followed by death remains elusive even after reviewing the literature, gathering unpublished data, and discussing the situation with colleagues. Did that onion retain some rodent or human odor that could have attracted the snake? Or was this merely an odd choice and a misguided attempt to feed on an ingestible object by that particular individual?
At $2215 \mathrm{~h}$ on 6 October 2015 adjacent to the normally busy square in the suburban outskirts of Jabalpur, Madhya Pradesh, VS observed another individual (total length -157 $\mathrm{cm}$ ) swallowing a long, somewhat rolled piece of cloth (Fig. 2). The late hour was unusual for this normally diurnal species but the presence of high-intensity street lamps might account for the prolonged activity period. Only $8 \mathrm{~cm}$ of the $38-\mathrm{cm}$ long cloth had been swallowed when VS interrupted the process. During the approximately 50 -min period when the snake attempted to swallow the cloth, VS prevented complete swallowing by holding onto the exposed portion and eventually induced regurgitation. The folded inner part of the cloth, which remained untouched by the snake's alimentary canal, was dry or randomly covered with greasy and dusty matter, suggestive of a discarded cloth used to clean vehicles. It likely retained a human odor that might have acted as a chemical stimulus.

In addition to these documented cases, earlier in July 2012, VS observed a juvenile of the same species swallowing

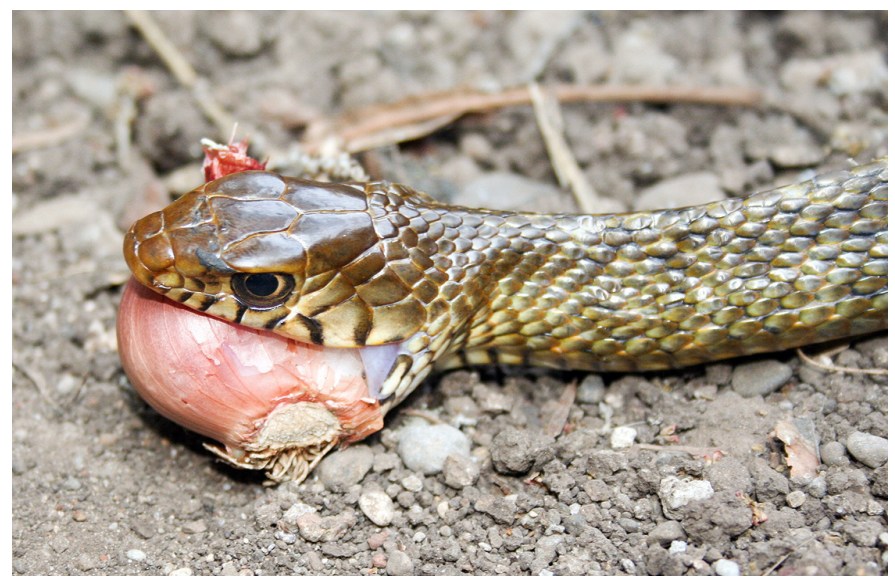

Fig. 1. An Oriental Ratsnake (Ptyas mucosa) consuming on onion in Satara, Maharashtra, India. Photograph (C) Amit Sayyed. 


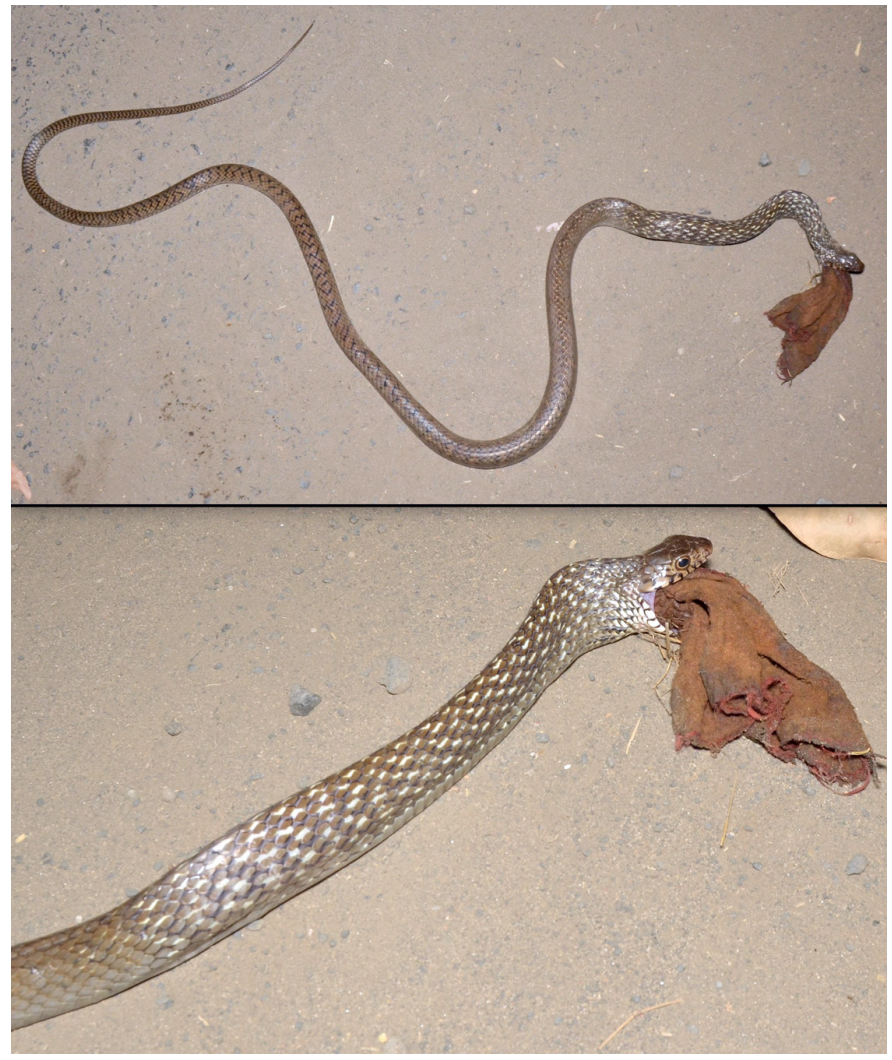

Fig. 2. A medium-sized Oriental Ratsnake (Ptyas mucosa) consuming a rolled piece of cloth in Jabalpur, Madhya Pradesh, India. Photograph (C) Vivek Sharma.

a male contraceptive discarded in a garden. The snake escaped into dense lantana bushes before any photographs were taken. In October 2014, VS observed another individual swallowing old discarded socks. Arpit Jain (pers. comm.) described yet another individual in March 2015 in Indore, Madhya Pradesh, feeding on a discarded polythene roll that appeared to have retained some salvageable edible material.

The inanimate objects taken by snakes all appeared to involve the retention of some attractive chemical stimulus. Although we believe the retention of animal odors unlikely in the case of the onion, Lillywhite et al. (2008) demonstrated that Florida Cottonmouths actively consumed algae with a chemical (fish) stimulus but algae without a fish odor were ignored. The consumption of the onion also differed from the observations of Dalziel (1937) and Irvine (1953), during which snakes consumed fruits, in that the snake died after eating the onion. Also, onions are unlikely to be infested by insects like the sweet fruits recorded by Mookerjee (1946).

Oriental Ratsnakes are frequently encountered in and around human habitations (Whitaker and Captain 2004), where rodents are common. Various artificial materials carrying a human or other mammalian odor could lure an active feeder like Ptyas mucosa. If, as suggested by our observations, consumption of such inanimate objects is not rare, further studies might examine the extent of digestion of such unusual objects, positive or negative effects on the health of a snake, any nutritive value of inanimate items consumed by snakes, and the potential impact on populations of snakes in these situations. Such studies could even lead to the development of artificial snake attractants for purposes of scientific or commercial collections.

\section{Acknowledgements}

We thank A. Shah and U. Somwanshi for assistance in the field and David Bird for providing some useful literature. We also thank H. Joshi, S. Thakur, A. Jain, and Z. Khan for constructive discussions on the subject.

\section{Literature Cited}

D’Abreu, E.A. 1911. Do snakes swallow stones? The Journal of the Bombay Natural History Society 21: 281.

Dalziel, J.M. 1937. The Useful Plants of West Tropical Africa. Crown Agents for the Colonies, London, United Kingdom.

DeVault, T.L. and A.R. Krochmal. 2002. Scavenging by snakes: An examination of the literature. Herpetologica 58: 429-436.

Greene, H.W. 1997. Snakes: The Evolution of Mystery in Nature. University of California Press, Berkeley.

Hughes, B. 1968. Snake killed by plant burr. British Journal of Herpetology 4: 39.

Irvine, F.R. 1953. Herbivorous snakes. British Journal of Herpetology 1: 173.

Lillywhite, H.B., C.M. Sheehy, and F. Zaidan. 2008. Pitviper scavenging at the intertidal zone: An evolutionary scenario for invasion of the sea. BioScience 58: 947-955.

Mookerjee, S. 1946. Mango-fruit-On the menu of the Common Python (Python molurus). The Journal of the Bombay Natural History Society 46: 733.

Perry, F.L. 1954. [Correspondence]. British Journal of Herpetology, 1: 225.

Whitaker, R. and A. Captain. 2004. Snakes of India: The Field Guide. Draco Books, Chennai, India. 